OPEN ACCESS

Edited by:

Xin Huang,

Nanjing University, China

Reviewed by:

Michael Edward Deary,

Northumbria University,

United Kingdom

Katarzyna Nowińska,

Silesian University of Technology,

Poland

*Correspondence:

Hongyan Liu

hyliu@gzu.edu.cn

Specialty section:

This article was submitted to

Toxicology, Pollution and the

Environment,

a section of the journal

Frontiers in Environmental Science

Received: 16 September 2021

Accepted: 03 February 2022

Published: 25 February 2022

Citation:

Yu E, Liu H, TuY, GuX, Ran X, Yu Z and Wu P (2022) Superposition Effects of Zinc Smelting Atmospheric Deposition on Soil Heavy Metal Pollution Under

Geochemical Anomaly.

Front. Environ. Sci. 10:777894. doi: 10.3389/fenvs.2022.777894

\section{Superposition Effects of Zinc Smelting Atmospheric Deposition on Soil Heavy Metal Pollution Under Geochemical Anomaly}

\author{
Enjiang $Y u^{1}$, Hongyan $\mathrm{Liu}^{2,3 *}$, Yu Tu${ }^{2}$, Xiaofeng $\mathrm{Gu}^{2}$, Xiaozhui Ran ${ }^{2}$, Zhi $\mathrm{Yu}^{1,4}$ and $\mathrm{Pan} W \mathrm{Wu}^{1,3}$ \\ ${ }^{1}$ College of Resources and Environmental Engineering, Guizhou University, Guiyang, China, ${ }^{2}$ College of Agriculture, Guizhou \\ University, Guiyang, China, ${ }^{3}$ Key Laboratory of Karst Georesources and Environment of Ministry of Education, Guizhou University, \\ Guiyang, China, ${ }^{4}$ Research and Design Institute of Environmental Science of Guizhou Province, Guiyang, China
}

Guizhou Province is covered by a large area of carbonate rocks where, with a higher background of heavy metals under the geochemical anomaly, more than $3.6 \times 10^{5}$ ha of heavy metal-contaminated soil in the northwest area is related to historical indigenous zinc smelting. To explore the superposition effect of industrial source atmospheric deposition on soil, two watersheds were selected for study: 1) Maoshui reservoir watershed (MS), where there is a zinc smelting plant, and 2) Haishe lake watershed (HS), which was the control. We collected atmospheric depositions and soil for 3 years and analyzed Cadmium $(\mathrm{Cd})$, lead $(\mathrm{Pb})$, chromium ( $\mathrm{Cr})$, copper $(\mathrm{Cu})$, nickel (Ni), and zinc $(\mathrm{Zn})$ content. The results show that the heavy metals in the atmospheric deposition of the pollution watershed in MS were much higher than those in the control site, HS. The deposition fluxes of $\mathrm{Cd}, \mathrm{Pb}, \mathrm{Cr}, \mathrm{Ni}$, and $\mathrm{Zn}$ in MS were $27.8,602,145,43.9$, and 2,225 $\mathrm{mg} \cdot \mathrm{m}^{-2} \cdot \mathrm{a}^{-1}$, respectively, and were 1.37-2.01 times higher than in HS. Soil heavy metals in MS were 1.01-5.69 times higher than in HS. The elevated concentrations were found focused from northeast to southwest around the plant but was distributed uniformly in $\mathrm{HS}$. The average concentration of $\mathrm{Cd}, \mathrm{Pb}$, and $\mathrm{Zn}$ in the soil was $6.54,67.4$, and $264 \mathrm{mg} \cdot \mathrm{kg}^{-1}$, respectively, in HS, which represents a high geochemical background even without pollution. After 13 years of deposition by prediction, the contribution of the atmospheric deposition on the soil in the zinc-smelting area was lowest, at $5.10 \%$, for $\mathrm{Ni}$, and highest, at $17.9 \%$, for $\mathrm{Cd}$. Principal component analysis of atmospheric deposition and soil heavy metals reflected that the pollution sources in MS were more diversification than those in HS. Zinc smelting atmospheric deposition showed superposition effects on the accumulation of heavy metals in soil under the geochemical anomaly in this region.

Keywords: atmospheric deposition, zinc smelting, heavy metals, soil, geochemical anomaly

\section{INTRODUCTION}

The term "geochemical anomaly" refers to the deviation of chemical element content distribution or other chemical indexes from the normal geochemical model in a given space or area (Luo et al., 2019; Zhang and Song, 2018). Guizhou Province is covered by a large area of carbonate rocks and, with its much higher background of heavy metals than other provinces, represents a geochemical anomaly. 


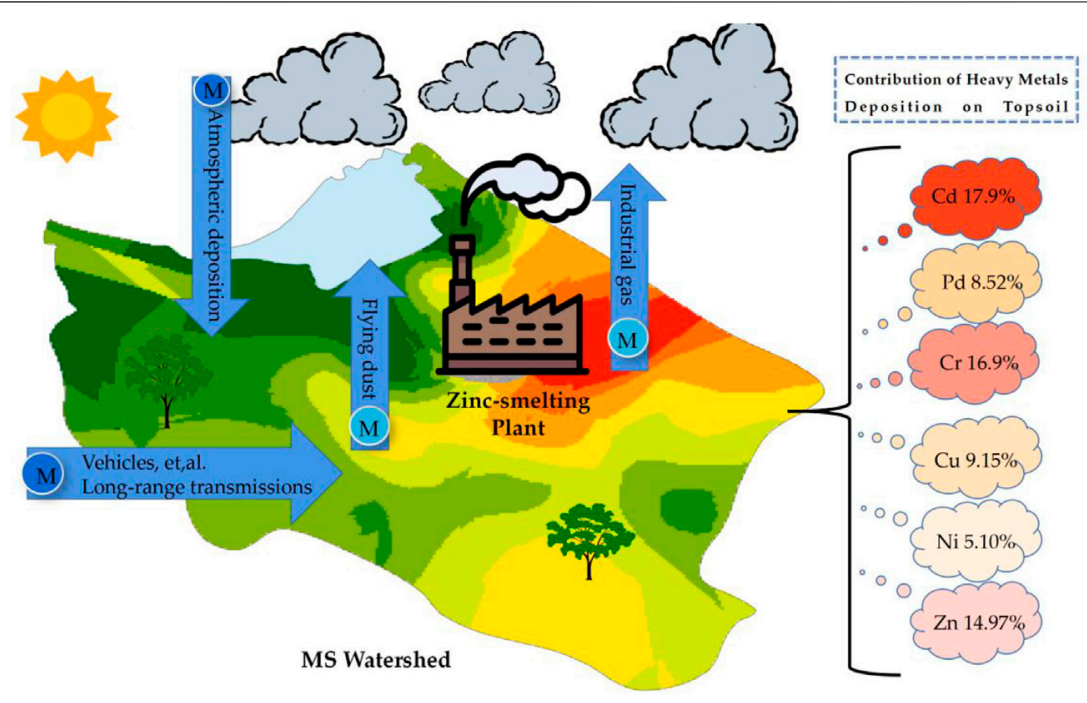

GRAPHICAL ABSTRACT | Superposition effects of zinc smelting atmospheric deposition on soil heavy metal pollution.

The background values of the heavy metals $\mathrm{Cd}, \mathrm{Pb}, \mathrm{Cr}, \mathrm{Cu}, \mathrm{Ni}$, and $\mathrm{Zn}$ are $0.4668,33.40,139.6,66.58,56.89$, and $111.4 \mathrm{mg} \mathrm{kg}^{-1}$ (He and Chen, 2002), respectively, and are much higher than the national background value (Luo and Liu, 2020). In the face of such a geochemical anomaly, the geological source becomes an important source of heavy metals in atmospheric deposition (Wang et al., 2015).

Atmospheric deposition is an important means by which heavy metals can enter the soil, such as through irrigation water, sewage sludge use, and so on (Cao et al., 2020; Yu and Liu, 2021). Air pollutants enter the water and soil environment in the form of depositions (Yu et al., 2019), causing environmental problems such as water eutrophication, soil acidification, and heavy metal pollution in water and soil (Xia et al., 2014). Sedimentation flux and sedimentation rate are the main research indexes of atmospheric deposition. Some studies have investigated the deposition rate of heavy metals in the atmosphere on a local scale (Kara et al., 2014; Pan and Wang, 2015; Shamsaddin et al., 2020), but reported few results of a closed region.

Due to the limited critical radius of atmospheric transport and the reduction of emissions caused by human activities, it is expected that the number of heavy metals deposited in the atmosphere in industrial areas will be higher than compared to those in natural ecosystems (Al-Khashman et al., 2013; Kiyoshi et al., 2019). Many studies have shown that atmospheric deposition can transport industrial compounds over long distances, causing pollution to the atmosphere and soil around factories (Hermanson et al., 2020; Xing et al., 2020a). The accumulation of heavy metals in atmospheric deposition in the ecosystem can more effectively be accurately reflected in closed regions (Kara et al., 2014; Pan et al., 2021). The atmospheric deposition of heavy metals in farmland soils in Hunan Province accounted for 51.24 94.74\% of the total input (Hunan, 2016) (Yi et al., 2018). The atmospheric deposition of the heavy metal Cd in nine counties in central and eastern Guangxi accounted for 90.65\% of the total input (Guangxi, 2014 2015) (Chen et al., 2019). The importation of heavy metals into surrounding soil by atmospheric deposition in industrial areas has also been reported (Sonia et al., 2013; Wang et al., 2018; Hernández-Pellón and Fernández-Olmo, 2019). Therefore, it is necessary to study the sources and impacts of soil heavy metal pollution around industrial areas.

There is more than $3.6 \times 10^{5}$ ha of heavy metal contaminated soil in northwest Guizhou Province, according to a national investigation of farmland soil pollution conducted in 2018. Guizhou Province has the maximum range of heavy metal pollution soil in China (more than $3.6 \times 10^{5} \mathrm{~h}$ ), and studies have indicated that this is rooted in zinc smelting that occurred 30 years ago in this region. Artisanal zinc smelting began 600 years ago in the region, and large-scale artisanal zinc smelting was conducted for about 20 years, from the 1980 s to 2004. In the absence of pollution treatment of waste gas, water, and mineral waste residue, the amount of waste residue reached 24 million tons and is still present in the environment today, causing serious heavy metal pollution (Luo et al., 2018; Zhou et al., 2020), which has resulted in severe ecological, environmental, and health risks (Peng et al., 2018). The artisanal zinc smelting process used indigenous methods: two major $\mathrm{Zn}$ ores, a sulfide ore in the form of sphalerite ( $\mathrm{ZnS})$, and a carbonate $\mathrm{Zn}$ ore in the form of smithsonite $\left(\mathrm{ZnCO}_{3}\right)$. These were mixed with coal as a reducing agent, placed in ceramic jars, and roasted for a few hours at a high temperature $\left(800^{\circ} \mathrm{C}\right)$, using coal as fuel to generate heat in a furnace to produce liquid metallic $\mathrm{Zn}$ (Figure 1). Therefore, in this study, we trace the soil pollution caused by the historical artisanal zinc smelting through one zinc oxide powder plant that carried out production in this region.

We selected two watersheds as closed regions to study the superposition effect of heavy metals in the atmospheric deposition on soil: 1) Maoshui reservoir watershed (MS), 


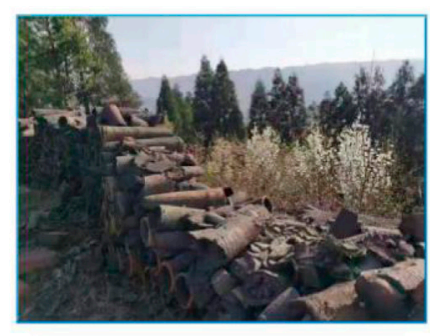

Historical Artisanal Zinc Smelting Pollution Site

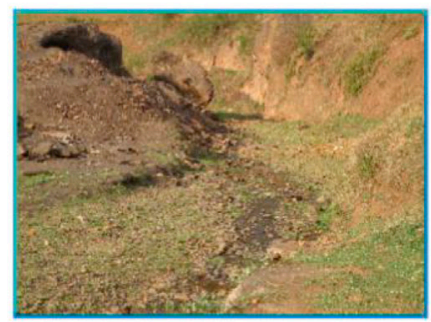

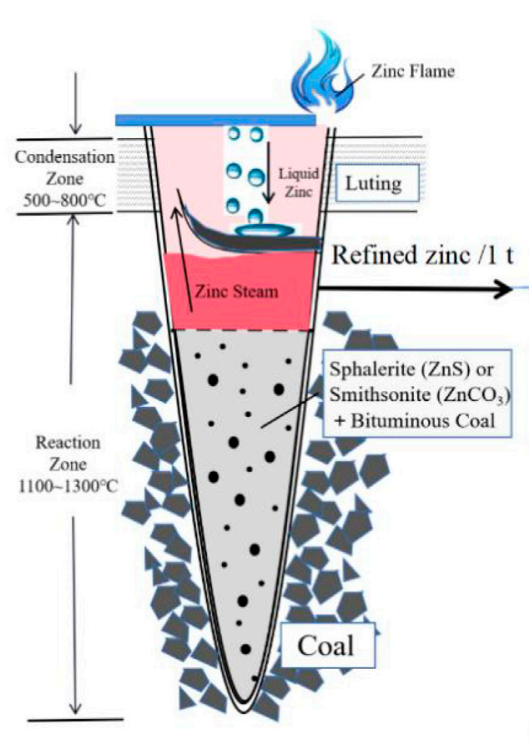

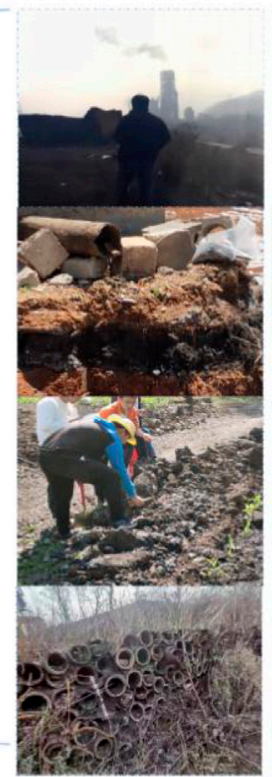

Exhaust

Gases

$/ 10000 \mathrm{~m}^{3}$

Coal

Cinder

$/ 1.0 \mathrm{t}$

\section{Mineral}

Waste

Residue

$/ 1.5 \sim 2.0 \mathrm{t}$

Pottery

Crucible

Residue

$/ 0.5 \sim 0.8 t$

FIGURE 1 | Schematic diagram of historical artisanal zinc smelting.

which has a zinc smelting plant, and 2) Haishe lake watershed (HS), which was the control. The main objectives of this study were to: 1) test the $\mathrm{Cd}, \mathrm{Pb}, \mathrm{Cr}, \mathrm{Cu}, \mathrm{Ni}$, and $\mathrm{Zn}$ concentrations in wet and dry atmospheric deposition in different seasons; 2) determine the association between soil heavy metal content and atmospheric deposition; 3) predict the incremental content of heavy metals in topsoil from atmospheric deposition; and 4) trace the influence of historical artisanal zinc smelting on soil heavy metal pollution in the context of a geochemical anomaly.

\section{MATERIALS AND METHODS}

\subsection{Study Area}

The study area was Weining County, an administrative area of Bijie City located in Guizhou Province in southwestern China. The area has been affected by lead and zinc smelting and contains a geological anomaly (Figure 2). In the fourth quarter of the test area, spring levels of precipitation reached $163 \mathrm{~mm}$, while summer, autumn, and winter levels were 476.8, 182.9, and $180 \mathrm{~mm}$, respectively. Weining County has a subtropical monsoon climate. The average annual temperature is $11.2^{\circ} \mathrm{C}$, with a $3.9^{\circ} \mathrm{C}$ average in January, and $17.0^{\circ} \mathrm{C}$ in July. In Weining, southerly winds prevail from January to September, switching to northerlies from October to December, and the average wind speed is $3.5 \mathrm{~m} / \mathrm{s}$ (Guizhou Meteorological Bureau). Weining county is one of the most important artificial $\mathrm{Zn}$ mining regions in China. $\mathrm{Zn}$ smelting activities began in the last century but ceased in 2004 due to grave issues with environmental pollution (Luo et al., 2018).

The two watersheds studied, MS and HS, are located in the Karst landscape of Weining County, northwest Guizhou
Province, China (Figure 2). The two sites are part of the Permian Xuanwei Formation and contain yellow acid topsoil. The MS is located northwest of Jinzhong Town, Weining County $\left(26^{\circ} 47^{\prime} 10^{\prime \prime} N, 104^{\circ} 23^{\prime} 8^{\prime \prime} E\right)$ at an altitude of about $2,122 \mathrm{~m}$ and covers an area of about $1.5 \mathrm{~km}^{2}$, a county-level highway serving as the boundary of the MS watershed northeast. The zinc smelting plant uses rotary kiln technology and was established in August 2006, the raw ore mean heavy metal content are $57.73 \mathrm{mg} / \mathrm{kg}$ for $\mathrm{Cd}, 29,850 \mathrm{mg} / \mathrm{kg}$ for $\mathrm{Pb}$, $94.27 \mathrm{mg} / \mathrm{kg}$ for $\mathrm{Cr}, 144.6 \mathrm{mg} / \mathrm{kg}$ for $\mathrm{Cu}, 32.75 \mathrm{mg} / \mathrm{kg}$ for $\mathrm{Ni}$, and $44,090 \mathrm{mg} / \mathrm{kg}$ for $\mathrm{Zn}$. HS is located north of Lushan Town, Weining County, at $26^{\circ} 48^{\prime} 14^{\prime \prime} N$, $104^{\circ} 23^{\prime} 42^{\prime \prime} E$ and served as the control area. This key watershed is unpolluted by industry and is protected by the county government because it supplies the lake at the center of the mountainous region. Its natural water is historically unused for irrigation or drinking. HS has an altitude of $2,110 \mathrm{~m}$ and an area of about $1.8 \mathrm{~km}^{2}$. The distance between MS and HS is approximately $6.8 \mathrm{~km}$ (Figure 2).

\subsection{Sample Collection and Determination}

\subsubsection{Atmospheric Deposition}

Samples of atmospheric deposition were collected each quarter (spring, summer, autumn, and winter) from May 2017 to May 2020. Wet and dry atmospheric depositions were collected at five sampling points in each experimental area, with three replicates for each sampling point (Figure 2). Polyethylene cylinders $(15 \mathrm{~cm}$ in diameter and $30 \mathrm{~cm}$ in height) were used to collect atmospheric depositions. The cylinders were mounted on $1.5 \mathrm{~m}$ tall frames on the flat roofs of local buildings at each sampling site, approximately $4-6 \mathrm{~m}$ above the ground. The height difference 


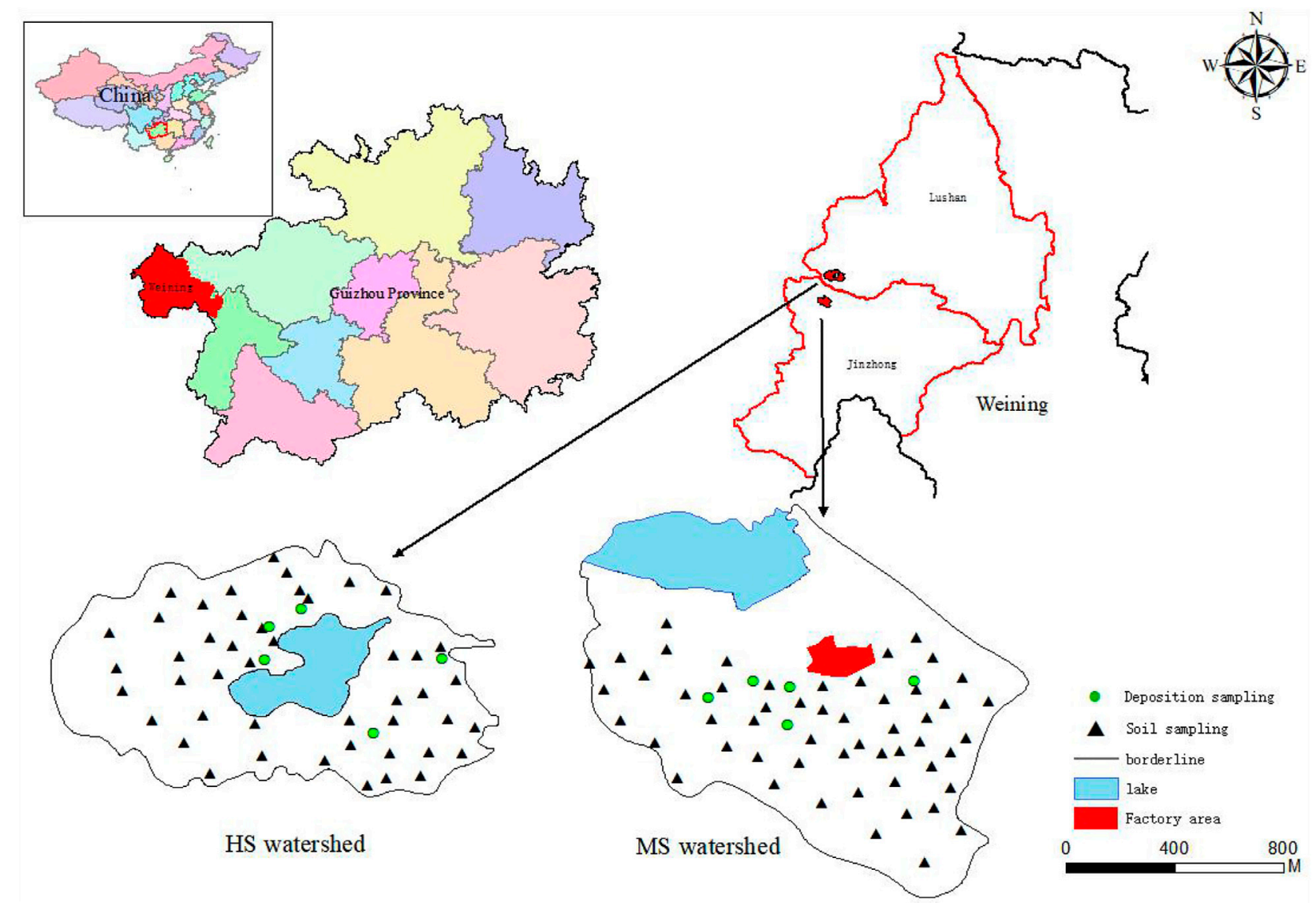

FIGURE 2 | Location of sampling sites in Weining County, Guizhou Province, China.

between roof, ground, and cylinder was set to minimize the contamination of the samples by re-suspended dust or soil from the ground or roof. Before installation, the cylinders were washed and soaked in a $5 \%$ nitric acid $\left(\mathrm{HNO}_{3}\right)$ bath for more than $2 \mathrm{~h}$ to remove potential contaminants. Three cylinders were installed at each site at the beginning of each quarter, and $100 \mathrm{ml} 1 \% \mathrm{HNO}_{3}$ was added to each cylinder to prevent the growth of microorganisms.

The upper liquid was collected in polyethylene bottles when the precipitation had reached halfway up the cylinders, and its total volume and weight were measured. After determining the $\mathrm{pH}$ value of the bottles, we reduced the $\mathrm{pH}$ value to below 2 by adding $1 \% \mathrm{HNO}_{3}$, preventing changes in the chemical species of the elements. We then refrigerated the bottles at $4^{\circ} \mathrm{C}$ for analysis. The remaining precipitate was filtered with $0.45 \mu \mathrm{m}$ polyester fiber filters, and the volume of filtrate was recorded, then discarded. The filter cake was air-dried or dried at temperatures lower than $65^{\circ} \mathrm{C}$, and its weight was then recorded. At this point, the dried precipitates were ready for analysis. Samples from each cylinder for each quarter were combined into one sample and tested. The annual precipitation was collected, and the precipitation time and amount were recorded. This method duplicated that of Yi et al. (2018).

\subsubsection{Surface Soil}

The samples were taken between May 2017 and May 2020. To ensure an even distribution of the sites selected, systematic sampling using a regular grid was used (State Environmental Protection Administration of China, 2004). Soil samples were collected in December of each year, with 58 samples taken from MS and 46 from HS. Each sample was taken from the top $20 \mathrm{~cm}$ of soil at a density of 1 sample $/ 40,000 \mathrm{~m}^{2}$. The samples were airdried, ground, and passed through a 20 -mesh $(<0.84 \mathrm{~mm})$ nylon sieve. Four surface soil sub-samples were combined to make a representative soil sample. These sampling methods complied with relevant specifications (State Environmental Protection Administration of China, 2004).

\subsection{Sample Analysis}

\subsubsection{Atmospheric Deposition (Precipitation)}

The heavy metal $(\mathrm{Cd}, \mathrm{Pb}, \mathrm{Cr}, \mathrm{Cu}, \mathrm{Ni}$, and $\mathrm{Zn})$ content of precipitation was analyzed according to the microwave digestion method set out in National Environmental Standard HJ678-2013 (Ministry of Environmental Protection, 2014). After filtering the precipitation samples, samples of $25 \mathrm{ml}$ were transferred to the microwave digestion tank, where $1 \mathrm{ml}$ of $\mathrm{H}_{2} \mathrm{O}_{2}(30 \%)$ and $5 \mathrm{ml}$ of $\mathrm{HNO}_{3}$ were added to each sample. 
These were placed in a ventilation cabinet, and placed in the microwave digestion instrument. The temperature of the microwave digestion instrument temperature was set at $180^{\circ} \mathrm{C}$. This temperature was reached in $10 \mathrm{~min}$ and was sustained for $15 \mathrm{~min}$. The digestion tank was then removed and cooled to room temperature, whereupon the solution was transferred to a $50 \mathrm{ml}$ volumetric flask. The tank was then rinsed twice with deionized water and transferred to another $50 \mathrm{ml}$ volumetric flask, where it was topped up with deionized water, as required. The heavy metal content was determined by inductively coupled plasma mass spectrometer (ICP-MS; Thermo Fisher Scientific X2).

\subsubsection{Surface Soil}

Soil samples of $0.1 \mathrm{~g}$ were weighed and placed into the polytetrafluoroethylene inner tanks of the digestion kettle through a 100 -mesh sieve. $3 \mathrm{ml} \mathrm{HNO}_{3}$ (guarantee reagent) and $3 \mathrm{ml} \mathrm{HF}$ (guarantee reagent) were added and the sample was left for $8 \mathrm{~h}$. Then, $2 \mathrm{ml}$ of $\mathrm{HClO}_{4}$ (guarantee reagent) was added and placed in the metal outer tank of the digestion kettle to dissolve in the oven at $180^{\circ} \mathrm{C}$ for $12 \mathrm{~h}$. When the digestion was complete, the inner polytetrafluoroethylene tanks on the electric hotplate were heated to completely dry the acid and remove any HF residue. $1 \mathrm{ml}$ of $\mathrm{HNO}_{3}$ (guarantee reagent) was added to dissolve and the volume of $3 \%$ diluted $\mathrm{HNO}_{3}$ (guarantee reagent) was fixed to $50 \mathrm{ml}$ before the heavy metal ( $\mathrm{Cd}, \mathrm{Pb}, \mathrm{Cr}, \mathrm{Cu}, \mathrm{Ni}$, and $\mathrm{Zn}$ ) concentrations were determined by inductively coupled plasma mass spectrometer (ICP-MS; Thermo Fisher Scientific X2).

\subsubsection{Atmospheric Deposition (Dry Precipitation)}

The levels of dried precipitate heavy metal were determined in the same way as for the surface soil.

\subsubsection{Predicted Concentrations of Heavy Metals in Deposited Atmospheric Emissions}

A survey of the job site revealed that the zinc smelting plant used a desulfurization tower and a chimney of $30 \mathrm{~m}$, which emitted smoke outlet with a temperature of $240^{\circ} \mathrm{C}$, the annual output of zinc oxide was 3,000 $\mathrm{t}$ and the dust output was 4,000 t. The impact range of emissions was $1.5 \mathrm{~km}$, according to the Gaussian model of elevated continuous point sources developed by Hao et al. (2010).

The ground-level deposition of dust from industrial atmospheric emissions was predicted using Hao et al.'s model (2010). The origin is the zinc smelting plant, the $x$-axis displays the wind direction with the average positive wind direction on the left side of the axis. The $y$-axis is perpendicular to the $x$-axis, the $z$-axis is perpendicular to the horizontal plane, and the upward direction is the positive direction; namely, the right-hand coordinate system. The formula for establishing ground concentrations is

$$
\rho(x, y, 0)=\frac{Q}{\pi \bar{\mu} \sigma_{\mathrm{y}} \sigma_{z}} \exp \left(-\frac{y^{2}}{2 \sigma_{\mathrm{y}}^{2}}\right) \exp \left(-\frac{H^{2}}{2 \sigma_{z}^{2}}\right)
$$

where $\sigma_{y}$ is the standard deviation of pollutant distribution in the $y$ direction of a smoke stream at $x$ distance from origin, $\mathrm{m} ; \sigma_{z^{-}}$is the standard deviation of pollutant distribution in the $y$ direction of a smoke stream at distance $z$ from origin, $\mathrm{m} ; \rho$ - is the concentration of pollutants at any point, $\mathrm{g} \cdot \mathrm{m}^{-3} ; \bar{\mu}$ - is the mean wind speed, $\mathrm{m} \cdot \mathrm{s}^{-1}$; and $Q$ is the source strength, $\mathrm{g} \cdot \mathrm{s}^{-1} ; H$ is source valid high (the sum of the chimney height and the raised height of the soot), $\mathrm{m}$.

The coefficients of $\sigma_{y}, \sigma_{z}, Q$, and $\mathrm{H}$ refers to the methodological guidelines of technical guidelines on environmental impact assessment for the atmospheric environment, HJ/T 2.1 2.3-93 (State Bureau of Environmental Protection, 1994).

\subsubsection{The Contribution of Depositions to Soil}

The values of the $\mathrm{Cd}, \mathrm{Pb}, \mathrm{Cr}, \mathrm{Cu}, \mathrm{Ni}$, and $\mathrm{Zn}$ concentrations in the digests were converted into deposition fluxes $\left(\mathrm{mg} \cdot \mathrm{m}^{-2} \cdot \mathrm{a}\right)$ based on the duration of sampling and the aperture size of each cylinder. To further investigate the potential implications of elevated depositions of atmospheric heavy metals, attempts were made to estimate surface soil contamination in the region using the calculated annual flux of atmospheric deposition. The contribution of deposition to soil was calculated as the ratio of deposition flux to the average concentration of surface soil heavy metal in the test areas, assuming a soil bulk density of $1,300 \mathrm{~kg} \mathrm{~m}^{-3}$ (Cao et al., 2020). The worst-case scenario was calculated using the same assumption that atmospheric deposition was the sole source of heavy metal in the soil and was retained in the top $20 \mathrm{~cm}$ of arable soils (Cao et al., 2020).

\subsubsection{Quality Control and Quality Analyse}

All glassware was soaked in a $5 \%$ nitric acid solution for more than $2 \mathrm{~h}$ before use and then triple-rinsed with DI water. Along with the triplicate samples, analytical blanks and a standard reference soil (Gss-5) were included in the digestion of each sample batch. The recovery rates of heavy metals in the reference soil were $86.7-113.3 \%$ (Mean $=93.2 \%$ ) for Cd, 94.8-105.3\% $($ Mean $=98.6 \%)$ for $\mathrm{Pb}, 94.3-105.9 \%($ Mean $=101.3 \%)$ for $\mathrm{Cr}$, 95.8-104.2\% $($ Mean $=101.2 \%)$ for $\mathrm{Cu}, 90.0-110.0 \%($ Mean $=$ $102.6 \%$ ) for $\mathrm{Ni}$, and $94.9-105.1 \%$ (Mean $=98.8 \%$ ) for $\mathrm{Zn}$.

The multi-element standard solution used by ICP-MS to determine the samples complied with national standard GSB 04-1767-2004. Standard reference materials (GSB 04-1767-2004) were used to validate the accuracy and precision of the analytic methods. The analytical quality control was precise, with the relative standard deviation being $<8.50 \%$. The limits of detection (LODs) of the ICP-MS for $\mathrm{Cd}, \mathrm{Pb}, \mathrm{Cr}, \mathrm{Cu}, \mathrm{Ni}$ and $\mathrm{Zn}$ were $0.03,2$, $5,2.4,4$, and $44 \mathrm{mg} / \mathrm{kg}$, respectively.

\subsection{Statistical Analysis}

The experimental area was obtained from a satellite map, measured on site via GPS (Trimble GEO 7X, Shanghai Navearth, Shanghai). Descriptive statistical analyses and plotting of figures were carried out using Origin 9.0 (Origin Lab Corporation, Northampton, MA) and Excel 2013 (Microsoft Corp., Waltham, MA, United States); Kriging interpolation was conducted using ArcGIS 10.6. Summary statistics were used to calculate the average values, standard deviations and analysis of variance by using SPSS version 22.0. One-way analysis of variance 

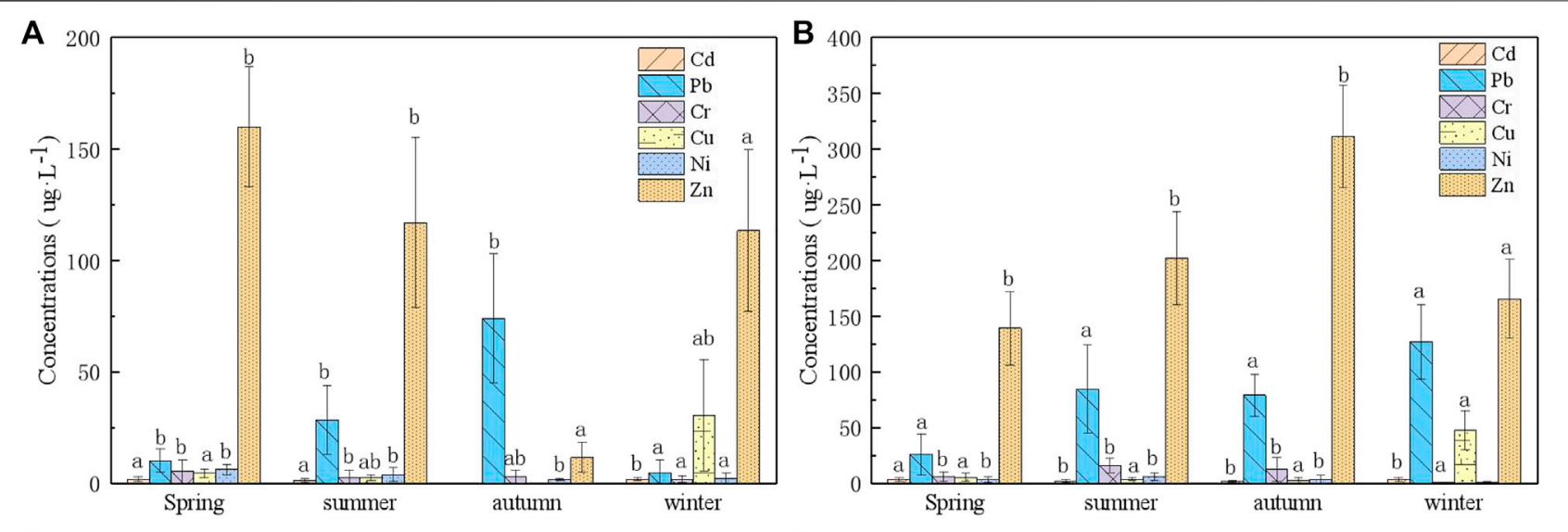

C

D
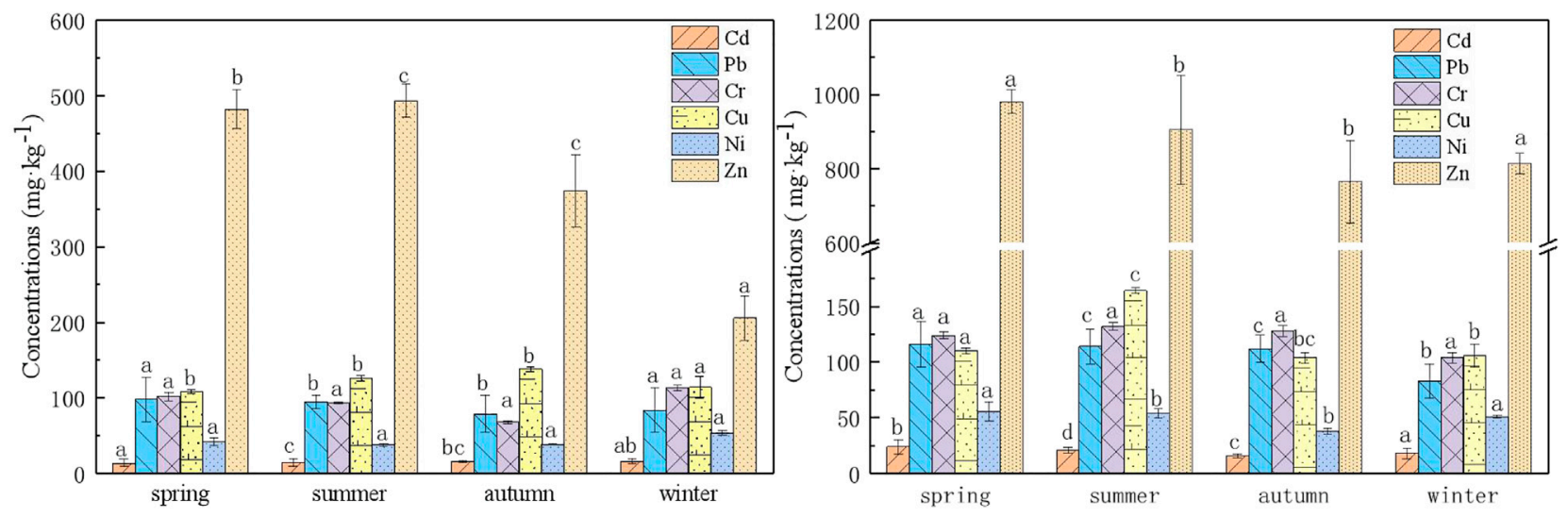

FIGURE 3 | Heavy metal concentration of atmospheric deposition: (A) HS wet deposition; (B) MS wet deposition; (C) HS dry deposition; (D) MS dry deposition. ANOVA was performed on the same elements in different seasons of samples from the same site.

(ANOVA) was conducted with the post hoc Tukey test method using a significance level of 0.05 to determine differences. Principal component analyses were conducted to compare different elements of samples from the same site. The rainfall data came from the official website of the Weining County Meteorological Bureau.

\section{RESULTS AND DISCUSSION}

\subsection{Heavy Metal Concentrations in Atmospheric Depositions}

3.1.1 Heavy Metal Concentrations in Wet Depositions Heavy metal concentrations in wet depositions at the control site (HS) were higher in spring and winter than those in summer and autumn (Figure 3A). This trend contrasted with local levels of precipitation, which were higher in the latter two seasons. Precipitation was a critical factor determining the flux of heavy metals in wet atmospheric deposition; the concentration of heavy metals in precipitation is affected by many factors, including the timeliness of the precipitation season and the interval of precipitation time ( $\mathrm{Li}$ and Jia, 2018). Zn reached the highest concentrations among the six heavy metals, with
$159.81 \pm 56.81 \mu \mathrm{g} \mathrm{L}^{-1}$ in spring, $116.77 \pm 68.15 \mu \mathrm{g} \mathrm{L} \mathrm{L}^{-1}$ in summer, $11.44 \pm 6.73 \mu \mathrm{g} \mathrm{L}^{-1}$ in autumn, and $113.28 \pm 86.32 \mu \mathrm{g} \mathrm{L}^{-1}$ in winter. In contrast, there were no obvious regularities in heavy metal concentrations in wet depositions at the pollution site (MS; Figure 3B). This phenomenon resulted from the local zinc oxide smelting facilities, whose operations contributed to the accumulation of heavy metals via atmospheric deposition all year round (Xing et al., 2020a).

Thus, heavy metal concentrations of wet deposition were much higher in MS than HS but the seasonal distribution was quite different. Moreover, the concentrations of all heavy metals in atmospheric depositions in the zinc smelting region were much higher than those in the nonindustrial region. This conclusion is consistent with the results of other studies (Cui et al., 2012; Cereceda-Balic et al., 2020). The concentration of these metals was higher at the MS site, in agreement with the proximity of this location to the zinc smelting plant (Hernández-Pellón and Fernández-Olmo, 2019).

\subsubsection{Heavy Metal Concentrations in dry Depositions}

Figure 3C shows that the concentrations of dry depositions of heavy metals at the control site (HS) were uniform across the four seasons, except for $\mathrm{Zn}$, which varied, reaching $493 \pm$ 
TABLE 1 | Deposition flux of heavy metals from atmospheric deposition in MS watershed/(mg. $\left.\mathrm{m}^{-2} \cdot \mathrm{a}^{-1}\right)$.

\begin{tabular}{|c|c|c|c|c|c|c|c|}
\hline Watershed & Atmospheric deposition & Cd & $\mathrm{Pb}$ & $\mathrm{Cr}$ & $\mathrm{Cu}$ & $\mathrm{Ni}$ & $\mathrm{Zn}$ \\
\hline \multirow[t]{3}{*}{ HS } & Wet deposition & 11.1 & 424 & 30.7 & 81.9 & 21.0 & 1,170 \\
\hline & Dry deposition & 2.76 & 16.7 & 18.8 & 21.0 & 8.49 & 122 \\
\hline & Total & 13.8 & 440 & 49.5 & 102 & 29.5 & 1,292 \\
\hline \multirow[t]{4}{*}{ MS } & Wet deposition & 20.3 & 564 & 101 & 34.9 & 24.8 & 1897 \\
\hline & Dry deposition & 7.54 & 38.3 & 44.0 & 41.1 & 19.1 & 328 \\
\hline & Total & 27.8 & 602 & 145 & 76.0 & 43.9 & 2,225 \\
\hline & deposition flux ${ }_{M S} /$ deposition flux ${ }_{H S}$ & 2.01 & 1.37 & 2.93 & 0.75 & 1.49 & 1.72 \\
\hline
\end{tabular}

$22.07 \mathrm{mg} \mathrm{kg}^{-1}$ in spring, $482 \pm 25.57 \mathrm{mg} \mathrm{kg}^{-1}$ in summer, $374 \pm$ $47.60 \mathrm{mg} \mathrm{kg}^{-1}$ in autumn, and $206 \pm 29.49 \mathrm{mg} \mathrm{kg}^{-1}$ in winter.

In MS, the most concentrated heavy metal in the dry depositions was Zinc (Figure 3D), with Cd recording the lowest concentrations across all seasons although these were far in excess of the background value of $0.4668 \mathrm{mg} \mathrm{kg}^{-1}$ (He and Chen, 2002) in northwestern Guizhou Province. Concentrations of all six elements from these two sites followed the order MS > HS, industrial site > non-industrial control site. Compared with the control, the concentration of $\mathrm{Zn}$ in dry depositions from the zinc smelting plant area was four times higher in MS than $\mathrm{HS}$, with levels of $\mathrm{Pb}, \mathrm{Cr}$, and $\mathrm{Cu}$ also significantly greater. The test region was located southwest of the zinc smelter, in the main wind direction of northwestern Guizhou (Guizhou Meteorological Bureau). Differences in the distribution of the heavy metal concentrations between this region and the control demonstrated that the main source of heavy metals in MS region was zinc smelting. These results corroborate previous research which found much higher concentrations of heavy metals in the test area than the control region (Xing et al., 2020b); studies have also shown that industrial emissions from the industrial belt exerted a notable influence on atmospheric deposition (Sonia et al., 2013; Wang et al., 2018; HernándezPellón and Fernández-Olmo, 2019).

\subsubsection{Deposition Fluxes of Heavy Metals}

In HS, the $\mathrm{Zn}$ deposition flux of $1,292 \mathrm{mg} \mathrm{m}^{-2} \cdot \mathrm{a}^{-1}$ was the largest among the six heavy metals, followed by $\mathrm{Pb}$, at $440 \mathrm{mg} \mathrm{m}^{-2} \cdot \mathrm{a}^{-1}$, with the lowest flux recorded for $\mathrm{Cd}$, at $13.8 \mathrm{mg} \mathrm{m}^{-2} \cdot \mathrm{a}^{-1}$ (see Table 1). The overall order of deposition flux for all elements was as follows: $\mathrm{Zn}>\mathrm{Pb}>\mathrm{Cu}>\mathrm{Cr}>\mathrm{Ni}>\mathrm{Cd}$. The pattern of deposition flux for MS was similar, with $\mathrm{Zn}$ recording the largest value, at $2,225 \mathrm{mg} \mathrm{m}^{-2} \cdot \mathrm{a}^{-1}$, followed by $\mathrm{Pb}$ at $602 \mathrm{mg} \mathrm{m}^{-2} \cdot \mathrm{a}^{-1}$, with $\mathrm{Cd}$ the lowest, at $27.8 \mathrm{mg} \mathrm{m}^{-2} \cdot \mathrm{a}^{-1}$. The overall order was $\mathrm{Zn}$ $>\mathrm{Pb}>\mathrm{Cr}>\mathrm{Cu}>\mathrm{Ni}>\mathrm{Cd}$. Other studies (Pereira et al., 2007; Pan and Wang, 2015; Chen et al., 2018; Cao et al., 2020) have recorded the same findings.

In this study, the deposition fluxes of $\mathrm{Zn}, \mathrm{Pb}$, and $\mathrm{Cd}$ were significantly higher than non-industrial zone study of Liang et al. (2014), who detected $\mathrm{Zn}$ levels of $205 \mathrm{mg} \mathrm{m}^{-2} \cdot \mathrm{a}^{-1}$, with $\mathrm{Pb}$ levels of $122 \mathrm{mg} \mathrm{m}^{-2} \cdot \mathrm{a}^{-1}$, and those of $\mathrm{Cd}, 3.06 \mathrm{mg} \mathrm{m}^{-2} \cdot \mathrm{a}^{-1}$. Furthermore, the deposition fluxes far exceeded those of China's Chang-Zhu-Tan industrial zone in our study (Cao et al., 2020). The main reasons for these difference that the type of industry was different (Cao et al., 2020) and, likewise, the geological background was not the same (Liang et al.,
2014). The analysis of samples collected over 3 years demonstrated that the dry atmospheric deposition input flux in HS was $190 \mathrm{~g} \mathrm{~m}^{-2} \cdot \mathrm{a}^{-1}$ and $378 \mathrm{~g} \mathrm{~m}^{-2} \cdot \mathrm{a}^{-1}$ in MS. Similarly, the wet deposition input flux in $\mathrm{HS}$ was $1,739 \mathrm{~g} \mathrm{~m}^{-2} \cdot \mathrm{a}^{-1}$, rising to $2,642 \mathrm{~g} \mathrm{~m}^{-2} \cdot \mathrm{a}^{-1}$ in MS. This confirms the deposition flux of heavy metals is higher in industrial than nonindustrial areas. To understand the accumulation of atmospheric settlement in the MS basin relative to the control HS more intuitively, we calculated the ratio of settlement flux between the two (Qiu et al., 2016). Table 1 shows that all five heavy metals (except for $\mathrm{Cu}$ ) had accumulated more in MS than HS, strengthening the conclusion that zinc oxide smelters are the main source of heavy metals in soils in the MS basin.

\subsection{Distribution of Heavy Metals in Soil 3.2.1 Concentrations in Surface Soil}

As Table 2 shows, the average heavy metal soil concentrations in HS were $6.54 \mathrm{mg} \mathrm{kg}^{-1}(\mathrm{Cd}), 67.4 \mathrm{mg} \mathrm{kg}^{-1}(\mathrm{~Pb}), 30.8 \mathrm{mg} \mathrm{kg}^{-1}(\mathrm{Cr})$, $44.6 \mathrm{mg} \mathrm{kg}^{-1}(\mathrm{Cu}), 47.6 \mathrm{mg} \mathrm{kg}^{-1}(\mathrm{Ni})$, and $264 \mathrm{mg} \mathrm{kg}^{-1}(\mathrm{Zn})$. These were $0.22-14.2$ times the background values ( $\mathrm{He}$ and Chen, 2002). The soil levels of $\mathrm{Cd}, \mathrm{Pb}$, and $\mathrm{Zn}$ soil were 14.2, 2.02 and 2.40 times than the background value, while those of $\mathrm{Cr}$, $\mathrm{Cu}$, and $\mathrm{Ni}$ were lower than the background value. These findings reflect the location of the study in a karst landscape, a geological anomaly that impacts soil levels of $\mathrm{Cd}, \mathrm{Pb}$, and $\mathrm{Zn}$ ( $\mathrm{He}$ and Chen, 2002). In HS soil samples, a small-moderate coefficient of variation $(\mathrm{CV})$ in heavy metal concentrations was detected (20.5-38.2\%), indicating that the soil was less affected by human activities at this site (see also Adimalla, 2020; Chai et al., 2021).

In $\mathrm{MS}$, the average concentrations of $\mathrm{Cd}, \mathrm{Pb}, \mathrm{Cr}, \mathrm{Cu}, \mathrm{Ni}$, and $\mathrm{Zn}$ in the soil were $8.43 \mathrm{mg} \mathrm{kg}^{-1}, 383 \mathrm{mg} \mathrm{kg}^{-1}, 46.5 \mathrm{mg} \mathrm{kg}^{-1}$, $45.0 \mathrm{mg} \mathrm{kg}^{-1}, 46.6 \mathrm{mg} \mathrm{kg}^{-1}$, and $805 \mathrm{mg} \mathrm{kg}^{-1}$, respectively. The heavy metal soil concentrations were $0.33(\mathrm{Ni})$ to $18.3(\mathrm{Cd})$ times the background value of the northwestern area of Guizhou Province (He and Chen, 2002). In total, the concentrations of heavy metals in soil were much higher in MS than HS, which were as much 5.68 and 3.05 times higher than in control HS, except for $\mathrm{Ni}$. The coefficients of variation for $\mathrm{Cd}, \mathrm{Cr}, \mathrm{Cu}$, and $\mathrm{Ni}$ in the soil ranged between 30.1 and $33.6 \%$, all medium levels, while those for $\mathrm{Pb}$ and $\mathrm{Zn}$ were 115 and $102 \%$, respectively. It could therefore be inferred that the concentration of heavy metals in the soil was not only affected by the local geology background but also by the surrounding small zinc smelters and other human activities (Adimalla, 2020; Chai et al., 2021). 
TABLE 2 | Concentration of heavy metals in soil/( $\left(\mathrm{mg}^{\mathrm{k}} \mathrm{kg}^{-1}\right)$.

\begin{tabular}{|c|c|c|c|c|c|c|}
\hline Index & Watershed & Min & Max & Mean \pm SD & CV(\%) & Background value \\
\hline \multirow[t]{2}{*}{$\mathrm{Cd}$} & HS & 1.44 & 12.9 & $6.54 \pm 2.50^{\mathrm{a}}$ & 38.2 & 0.4668 \\
\hline & MS & 1.26 & 13.9 & $8.43 \pm 2.83^{a}$ & 33.6 & \\
\hline \multirow[t]{2}{*}{$\mathrm{Pb}$} & HS & 33.9 & 91.8 & $67.4 \pm 13.8^{a}$ & 20.5 & 33.40 \\
\hline & MS & 65.0 & 2,968 & $383 \pm 442^{b}$ & 115 & \\
\hline \multirow[t]{2}{*}{$\mathrm{Cr}$} & HS & 9.39 & 42.9 & $30.8 \pm 8.11^{a}$ & 26.3 & 139.6 \\
\hline & MS & 26.0 & 108 & $46.5 \pm 14.0^{b}$ & 30.1 & \\
\hline \multirow[t]{2}{*}{$\mathrm{Cu}$} & $\mathrm{HS}$ & 15.1 & 70.4 & $44.6 \pm 10.5^{a}$ & 23.5 & 66.58 \\
\hline & MS & 15.3 & 229 & $45.0 \pm 28.9^{b}$ & 64.2 & \\
\hline \multirow[t]{2}{*}{$\mathrm{Ni}$} & HS & 13.2 & 79.7 & $47.6 \pm 14.8^{a}$ & 31.1 & 56.89 \\
\hline & MS & 12.2 & 70.4 & $46.6 \pm 14.1^{b}$ & 30.3 & \\
\hline \multirow[t]{2}{*}{$\mathrm{Zn}$} & $\mathrm{HS}$ & 90.8 & 369 & $264 \pm 68.9^{a}$ & 26.1 & 111.4 \\
\hline & MS & 156 & 5,279 & $805 \pm 825^{a}$ & 102 & \\
\hline
\end{tabular}

Different letters within the same column indicate significant differences at $\mathrm{p}<.05$ as determined by the Tukey's honestly significant difference pairwise comparisons test.

\subsubsection{Spatial Distribution of Heavy Metals}

The spatial distribution of the six heavy metals was calculated via Kriging interpolation through the semi-variance model (Figure 4). In general, all six heavy metals were uniformly distributed over the surface soil in HS, meaning that soil concentrations of heavy metal were influenced by the terrain and patterns of land use, rather than a source of pollution. In contrast, the soil in MS was characterized by obvious patterns in heavy metal distribution (Figure 4). High concentrations of $\mathrm{Cd}$, $\mathrm{Pb}, \mathrm{Cr}, \mathrm{Cu}$, and $\mathrm{Zn}$ were distributed from northeast to southwest around the zinc smelting plant, in distinction to the control site (although $\mathrm{Ni}$ was concentrated in the soil from southeast to northwest at levels only slightly higher than those recorded for HS). Figure 4 shows clearly that the differences between these distributions of heavy metals (except $\mathrm{Ni}$ ) are caused by the exhaust from the zinc smelting. From Table 2 as well as the spatial interpolation (Figure 4), it can be seen that the mean concentration of $\mathrm{Ni}$ is lower than the northwest Guizhou background value ( $\mathrm{He}$ and Chen, 2002) in both basins. The input of $\mathrm{Ni}$ is predominantly governed by the natural composition of the soil of the study region. The Ni CV was very low, signifying that natural and anthropogenic factors governed its spatial distribution (Adimalla, 2020).

This research found significantly higher soil concentrations of heavy metals than prior studies (Cai et al., 2019). While the main source of these was the local geochemistry, which was more influential than previously indicated ( $\mathrm{He}$ and Chen, 2002). A national investigation of farmland soil pollution in 2018 showed that $\mathrm{Cd}$ exceeded the national standard the most, followed by $\mathrm{Pb}$ and $\mathrm{Zn}$. This soil heavy metal pollution issue was well-supported by our experimental data. The effects of zinc smelting and historical artisanal zinc smelting in the area were also considerable. Atmospheric deposition and mineral waste residues are known to be the principal causes of soil contamination (Luo et al., 2018; Zhou et al., 2020). ArcGIS Kriging was used to capture the spatial variations of heavy metal distributions in the soil. Our comparison of the pollution caused by different forms of zinc smelting indicated that historical artisanal zinc smelting caused the highest levels of pollution, corroborating the findings of research carried out on other locations ( $\mathrm{Li}$ et al., 2013). Compounds in the waste produced by this form of smelting continue to decompose and contaminate local soil (Peng et al.,
2018). Even long after smelting operations had ended, exceptionally high levels of $\mathrm{Pb}, \mathrm{Zn}, \mathrm{Cd}$, and As arising from atmospheric deposition were still detected in the local surface soil of northwestern Guizhou Province (Zhou et al., 2020). These originate from a history of artisanal zinc smelting in the region lasting over 600 years.

\subsection{Principal Component Analysis of the Atmospheric Deposition and Soil Content of Heavy Metals \\ 3.3.1 Principal Component Analysis of the Atmospheric Deposition of Heavy Metals}

To perform the matrix analysis of rotated components (Table 3), components with eigenvalues of $>1$ were extracted. Two main components explained $92.5 \%$ of the variance in the source of the atmospheric deposition of heavy metals in HS. Component 1 (PC1) accounted for $70.5 \%$ of the total variance, while $\mathrm{Cd}, \mathrm{Pb}, \mathrm{Cu}$, and $\mathrm{Zn}$ had the largest loads, indicating a significant homology among these four elements. Given the high background levels of cadmium, lead, and zinc in northwestern Guizhou (Luo and Liu, 2020), the main source of atmospheric deposition may be the soil minerals caused by this geochemical anomaly. Clay and organic colloids can easily absorb heavy metals and fine particles of this soil are the primary source of atmospheric depositions with much higher heavy metal content in the area (Cereceda-Balic et al., 2020). Component 2 (PC2) accounted for $22.0 \%$ of the total difference, with $\mathrm{Cr}$ and $\mathrm{Ni}$ contributing the highest loads. $\mathrm{Cr}$ is a by-product of metal smelting, while $\mathrm{Ni}$ is typically produced by petroleum combustion, steel smelting, motor vehicle exhaust emissions and geological sources ( $\mathrm{Li}$ and Jia, 2018; Yasser et al., 2019; Wang et al., 2020; Pan et al., 2021).

The PCA of the atmospheric deposition of the heavy metals identified three main components explaining a total of $92.5 \%$ of the variance in the pollution recorded in MS. PC1 accounted for $52.3 \%$ of the total variance, with $\mathrm{Pb}$ and $\mathrm{Zn}$ the most important factors. PC2 accounted for $26.4 \%$ of the difference and $\mathrm{Cu}$ and $\mathrm{Cd}$ were the main eigenvalue factors. PC 3 accounted for $13.9 \%$ of the total variance, with $\mathrm{Cr}$ and $\mathrm{Ni}$ showing the strongest associations. Zinc smelting is the main source of $\mathrm{Pb}$ and $\mathrm{Zn}$ in atmospheric deposition ( $\mathrm{Gu}$ et al., 2021), demonstrating the importance of zinc oxide smelting and production to PC1. Atmospheric 


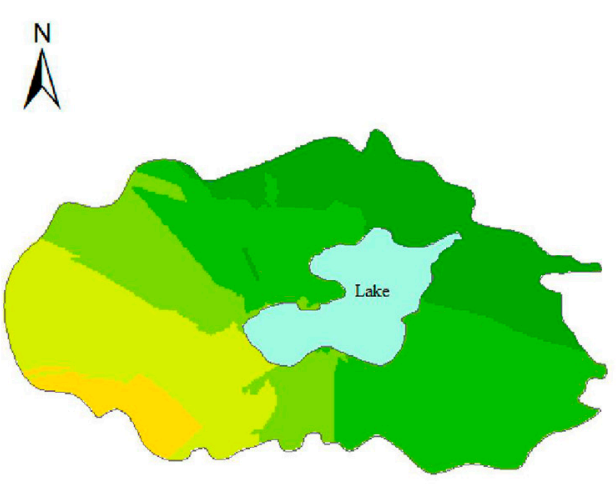

HS watershed
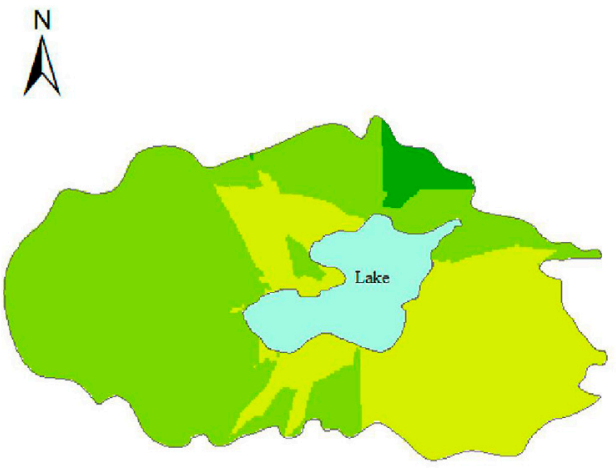

HS watershed

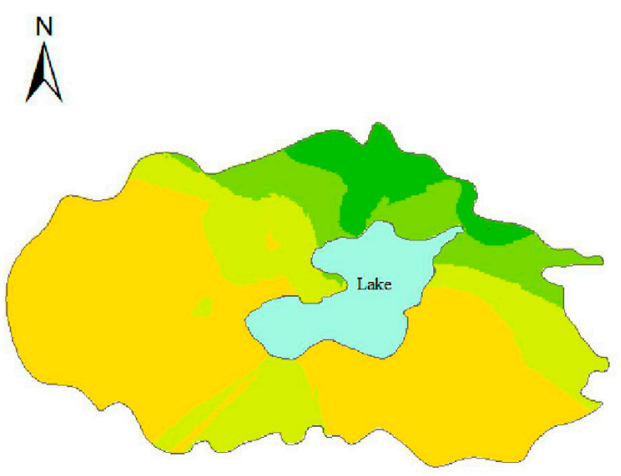

HS watershed

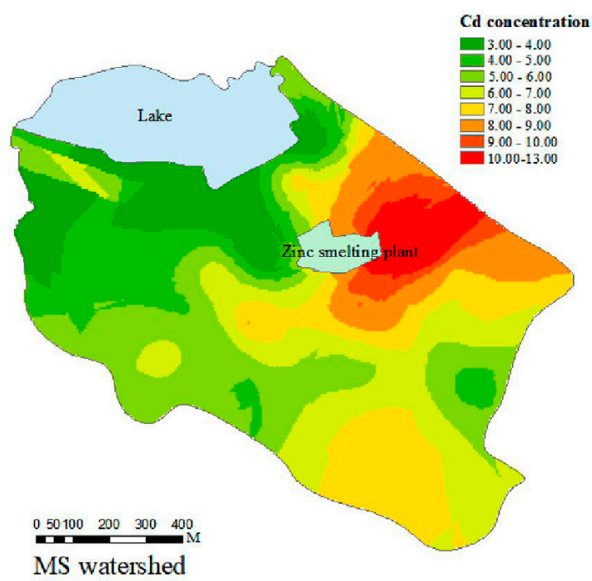

MS watershed
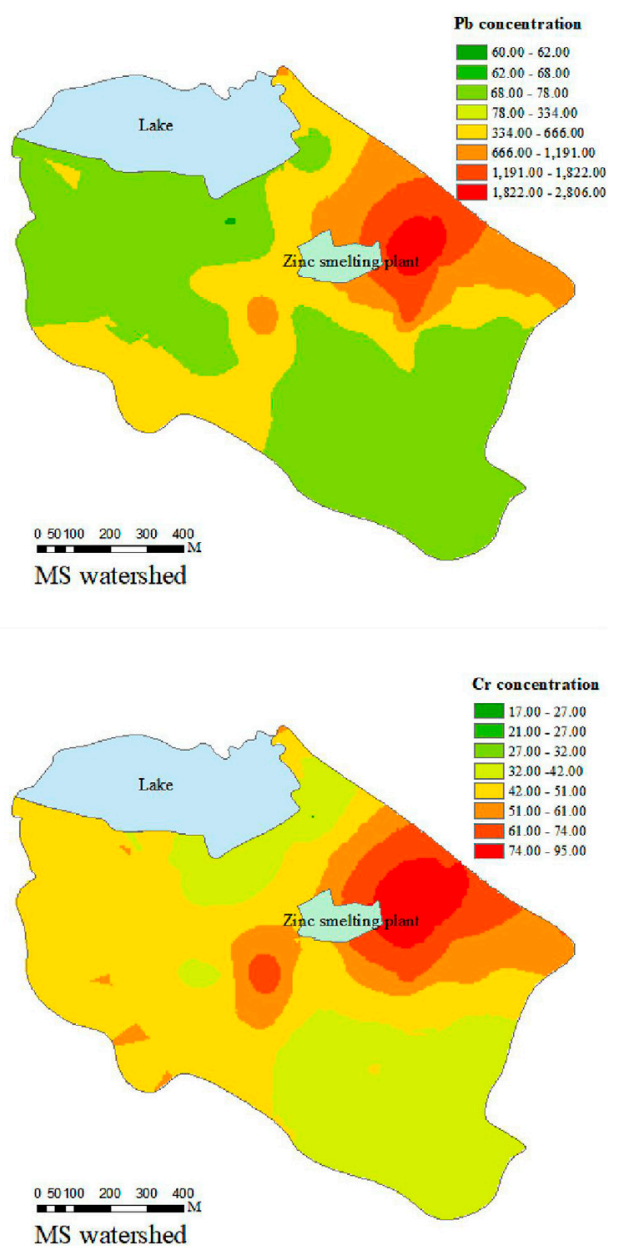

FIGURE 4 | Soil heavy metals distribution in 2 watersheds.

deposition varies according to the production methods of different industries (Garg et al., 2000; Li, 2020). Cadmium is produced by the smelting of non-ferrous metals (Liu et al., 2018), linking the high loadings of $\mathrm{Cu}$ and $\mathrm{Cd}$ in PC2 to zinc smelting, which PC2 was zinc smelting compound soil minerals. Chromium and nickel indicated sources such as traffic and 


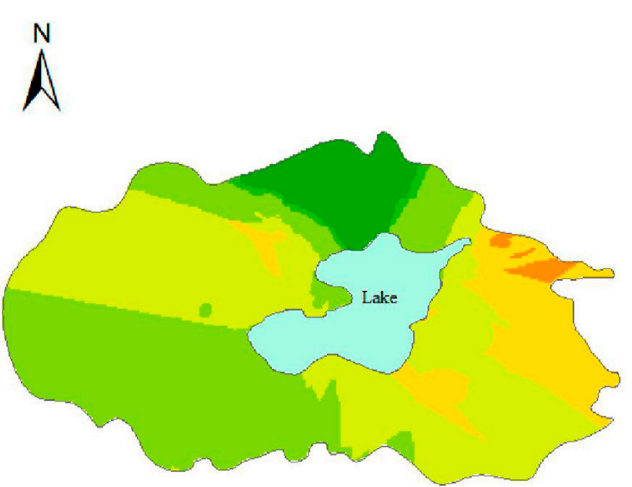

HS watershed

$$
\stackrel{N}{\Lambda}
$$

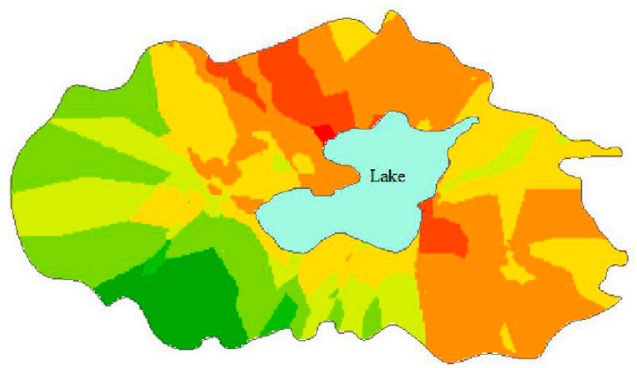

HS watershed<smiles>N=C1CC1</smiles>

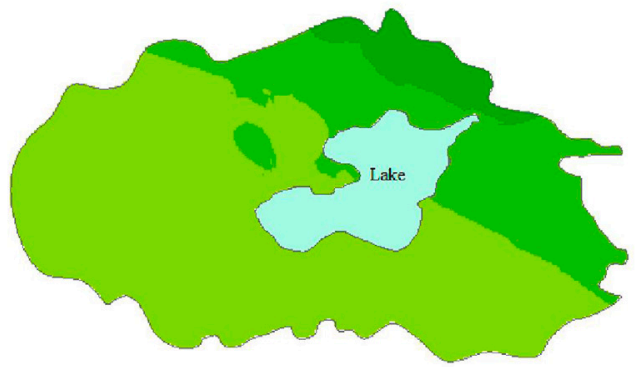

HS watershed

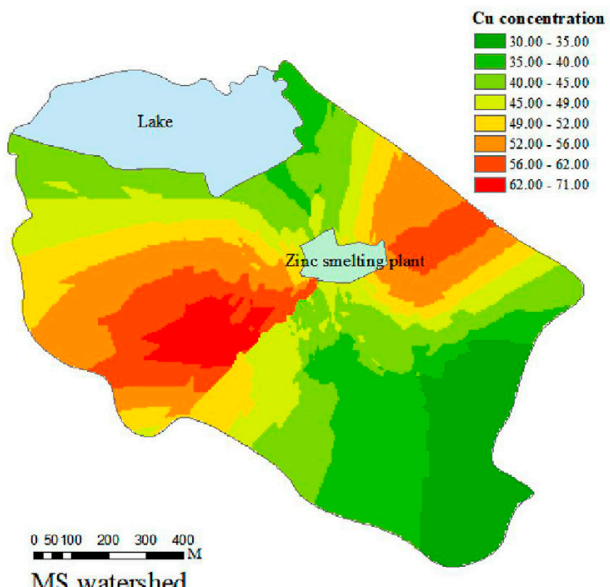

MS watershed

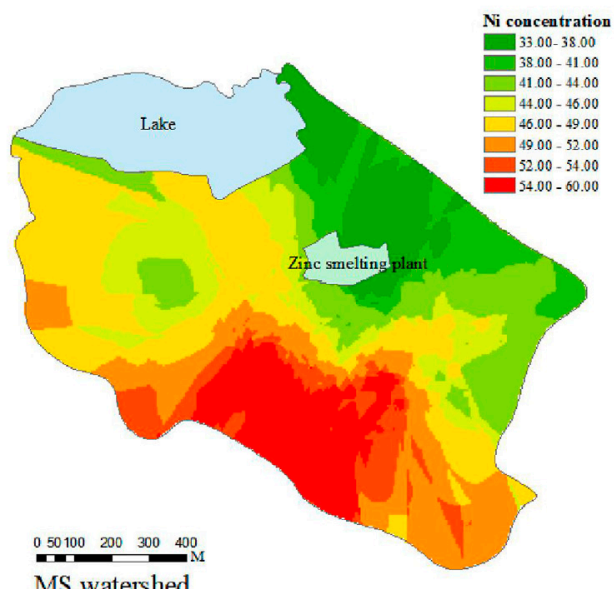

MS watershed

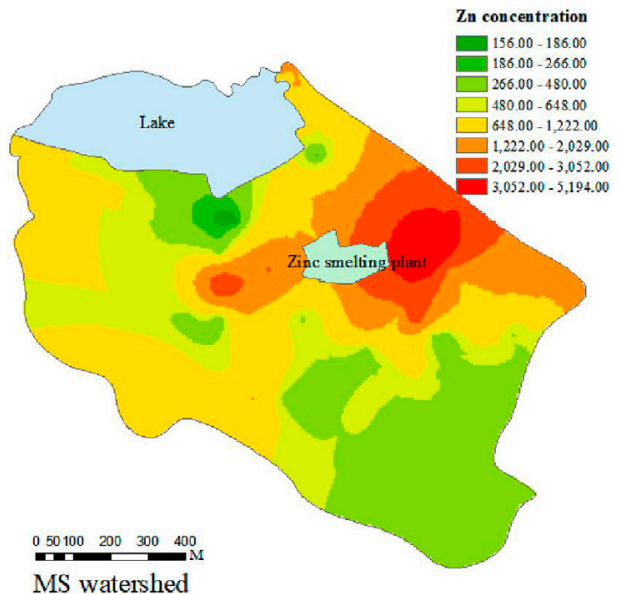

MS watershed metal smelting (Li and Jia, 2018; Yasser et al., 2019; Wang et al., 2020; Pan et al., 2021). The plate analysis of soil concentrations demonstrated the importance of geological sources in determining $\mathrm{Ni}$ levels and the re-suspended soil particles were also a potential source of atmospheric deposition (Xing et al., 2020b). Therefore, we contend that PC3 indicates the 
TABLE 3 | Principal component analysis of heavy metals in atmospheric deposition and soil.

\begin{tabular}{|c|c|c|c|c|c|c|c|c|c|c|}
\hline \multirow{3}{*}{$\begin{array}{l}\text { Watershed } \\
\text { Component }\end{array}$} & \multicolumn{5}{|c|}{ Atmospheric deposition } & \multicolumn{5}{|c|}{ Soil } \\
\hline & \multicolumn{2}{|c|}{ HS } & \multicolumn{3}{|c|}{ MS } & \multicolumn{2}{|c|}{ HS } & \multicolumn{3}{|c|}{ MS } \\
\hline & 1 & 2 & 1 & 2 & 3 & 1 & 2 & 1 & 2 & 3 \\
\hline $\mathrm{Cd}$ & 0.469 & -0.192 & 0.357 & 0.570 & -0.033 & 0.431 & 0.057 & 0.415 & 0.042 & 0.482 \\
\hline $\mathrm{Pb}$ & 0.438 & -0.354 & 0.538 & -0.217 & 0.019 & 0.441 & -0.352 & 0.488 & 0.077 & 0.215 \\
\hline $\mathrm{Cr}$ & 0.237 & 0.743 & 0.342 & 0.274 & -0.751 & 0.286 & 0.691 & -0.279 & 0.166 & 0.813 \\
\hline $\mathrm{Cu}$ & 0.453 & -0.137 & -0.186 & 0.699 & 0.234 & 0.425 & -0.278 & 0.475 & 0.054 & -0.180 \\
\hline $\mathrm{Ni}$ & 0.388 & 0.496 & 0.420 & 0.139 & 0.609 & 0.374 & 0.487 & -0.017 & 0.980 & -0.165 \\
\hline $\mathrm{Zn}$ & 0.420 & -0.146 & 0.505 & -0.214 & 0.091 & 0.465 & -0.282 & 0.532 & -0.034 & 0.008 \\
\hline Total & 4.23 & 1.32 & 3.14 & 1.58 & 0.832 & 3.97 & 1.01 & 3.20 & 1.01 & 0.90 \\
\hline$\%$ of Variance & 70.5 & 22.0 & 52.3 & 26.4 & 13.9 & 66.2 & 16.77 & 53.4 & 16.9 & 15.0 \\
\hline Cumulative \% & 70.5 & 92.5 & 52.3 & 78.6 & 92.5 & 66.2 & 83.0 & 53.4 & 70.3 & 85.3 \\
\hline
\end{tabular}

contribution of traffic and geological sources to the concentrations of heavy metals in depositions.

Compared to HS, the major source of heavy metal accumulation in atmospheric deposition in MS was the exhaust emitted from the local zinc oxide smelters. In both HS and MS, the atmospheric deposition of heavy metals originated in their geology.

\subsubsection{Principal Component Analysis of Heavy Metals in Soil}

Findings from the PCA of heavy metals in soil samples taken from the two watersheds revealed similar to those of atmospheric deposition.

The PCA extracted two major components which explained $83.0 \%$ of the total variance of heavy metals in the control site, HS. PC1 accounted for $66.2 \%$ of the total variance. The loading values of $\mathrm{Zn}$ (0.465), $\mathrm{Pb}$ (0.441), $\mathrm{Cu}(0.425)$, and $\mathrm{Cd}$ (0.431) were similar and derived from the geochemical makeup of the substrate. Our knowledge of the test region and prior research (Wang et al., 2015; Luo and Liu, 2020) indicated that PC1 was likely to be rooted in local geology. PC2 accounted for $16.7 \%$ of the total difference. The eigenvalues for $\mathrm{Cr}$ and $\mathrm{Ni}$ pointed to traffic, metal smelting, or other anthropocentric sources (Pan et al., 2021), and geological sources (Li and Jia, 2018; Yasser et al., 2019; Wang et al., 2020; Pan et al., 2021). However, the concentrations of $\mathrm{Cr}$ and $\mathrm{Ni}$ were below the background value, meaning that such sources were absent from the control site (He and Chen, 2002). Thus, the PCA indicated that the control watershed was mainly affected by geological sources.

A total of three components were able to explain $85.3 \%$ of the total variance of heavy metals in the polluted soil of MS, similar to the PCA of atmospheric depositions in this study area. PC1 accounted for $53.4 \%$ of the total variance. $\mathrm{Zn}, \mathrm{Pb}$, and $\mathrm{Cd}$ in the soil came from the residue of waste from the zinc oxide smelter, together with the input of atmospheric deposition and the residues of historical indigenous zinc smelting ( $\mathrm{Gu}$ et al., 2021). Cupric elements have multiple sources, such as mining production and steel smelting (Zhang et al., 2016). PC1 therefore represented the emission of industrial waste residue, the waste residue from historical indigenous zinc smelting, and exhaust emissions. PC2 accounted for $16.9 \%$ of the variance, with the factor loading of $\mathrm{Ni}$ in this component reaching 0.98 .
Nonetheless, Table 2 shows that the concentration of $\mathrm{Ni}$ in the soil did not exceed the background value of this heavy metal, which points to the sources of geology and the resuspended soil particles (Xing et al., 2020b). PC3 contributed $15.0 \%$ of the variance, with the Cr loading much higher, at 0.81 . Coal burning and chemical production are known to emit $\mathrm{Cr}$, and industrial atmospheric deposition was thus the most probable source of this pollution (Sternbeck et al., 2002; Vallius et al., 2003; Pan et al., 2021).

PCA with Varimax rotation was applied to heavy metal elemental of atmospheric depositions and soil to assess the possible emission sources (Cereceda-Balic et al., 2020). We identified two major emission sources of heavy metal content in atmospheric depositions and soil in HS, and three major emission sources in MS. Combined with the specific environmental situation of the MS, the findings pointed to more diverse sources of the heavy metals in MS soil, and one of the major means by which heavy metals can contaminate areas was found to be atmospheric deposition, as reported in other studies (Zheng et al., 2016).

\subsection{The Impact of Heavy Metals From Atmospheric Deposition on Soil}

As shown in Table 4, the zinc smelting plant was established in 2006, after 13 years of heavy metal deposition accumulated in the soil surface. Heavy metals from atmospheric deposition on soil after 13 years deposition were $\mathrm{Zn}>\mathrm{Pb}>\mathrm{Cr}>\mathrm{Cu}>\mathrm{Ni}>\mathrm{Cd}$, which were $120 \mathrm{mg} \mathrm{kg}^{-1} \sim 1.51 \mathrm{mg} \mathrm{kg}^{-1}$, respectively. The contribution rate of the atmospheric deposition on soil was $15.0 \%(\mathrm{Zn}) \sim 17.9 \%$ (Cd) (Table 4).

We predicted increments of heavy metal content from the atmospheric deposition based on the Gaussian model of elevated continuous point source (Hao et al., 2010), and the predicted heavy metal concentration is according to the proportion of dust in the bag dust collector in the zinc oxide smelter [Cd (311 $\left.\mathrm{mg} \mathrm{kg}^{-1}\right), \quad \mathrm{Pb} \quad\left(10,570 \mathrm{mg} \mathrm{kg}^{-1}\right), \quad \mathrm{Cr} \quad\left(1780 \mathrm{mg} \mathrm{kg}^{-1}\right), \quad \mathrm{Cu}$ $\left(735 \mathrm{mg} \mathrm{kg}^{-1}\right)$, Ni $\left(351 \mathrm{mg} \mathrm{kg}^{-1}\right)$, and $\left.\mathrm{Zn}\left(26,700 \mathrm{mg} \mathrm{kg}^{-1}\right)\right]$. After 13 years deposition, the order of heavy metals follow $\mathrm{Zn}$ $>\mathrm{Pb}>\mathrm{Cr}>\mathrm{Cu}>\mathrm{Ni}>\mathrm{Cd}$, that was the similarity as the monitoring values in this study, and the input contents were 
TABLE 4 | The impact of heavy metals from atmospheric deposition on soil.

\begin{tabular}{|c|c|c|c|c|c|c|c|}
\hline Watershed & Index & Cd & $\mathrm{Pb}$ & $\mathrm{Cr}$ & $\mathrm{Cu}$ & $\mathrm{Ni}$ & $\mathrm{Zn}$ \\
\hline HS & Deposition flux of heavy metals $/\left(\mathrm{mg} \mathrm{m}^{-2} \cdot \mathrm{a}^{-1}\right)$ & 13.8 & 440 & 49.5 & 102 & 29.5 & 1,292 \\
\hline \multirow[t]{3}{*}{ MS } & Deposition flux of heavy metals $/\left(\mathrm{mg} \mathrm{m}^{-2} \cdot \mathrm{a}^{-1}\right)$ & 27.8 & 602 & 145 & 76.0 & 43.9 & 2,225 \\
\hline & $\begin{array}{l}\text { Increment contents in topsoil after } 13 \text { years deposition/ } \\
\left(\mathrm{mg} \cdot \mathrm{kg}^{-1}\right)\end{array}$ & 1.51 & 32.6 & 7.91 & 4.10 & 2.40 & 120 \\
\hline & Contribution of deposition on soil/(\%) & 17.9 & 8.52 & 16.9 & 9.15 & 5.10 & 15.0 \\
\hline \multirow[t]{3}{*}{ MS Predictive value } & Deposition flux of prediction of emission/(mg m $\left.\mathrm{m}^{-2} \cdot \mathrm{a}^{-1}\right)$ & 17.5 & 381 & 100 & 41.3 & 19.7 & 1,500 \\
\hline & $\begin{array}{l}\text { Increment contents in topsoil after } 13 \text { years deposition/ } \\
\left(\mathrm{mg} \cdot \mathrm{kg}^{-1}\right)\end{array}$ & 0.95 & 20.6 & 5.44 & 2.23 & 1.07 & 81.2 \\
\hline & Contribution of deposition on soil/(\%) & 11.3 & 5.38 & 11.7 & 4.96 & 2.30 & 10.1 \\
\hline $\begin{array}{l}\text { Northwest of Guizhou } \\
\text { province }\end{array}$ & $\begin{array}{l}\text { Atmospheric deposition from historical artisanal zinc } \\
\text { smelting } /(t) \times 10^{4}\end{array}$ & $\begin{array}{c}0.56 \\
\sim 2.08\end{array}$ & $\begin{aligned} & 1.02 \\
\sim & 5.20\end{aligned}$ & $\begin{array}{c}2.00 \\
\sim 4.71\end{array}$ & $\begin{array}{l}1.00 \\
\sim 2.46\end{array}$ & $\begin{array}{c}0.89 \\
\sim 3.32\end{array}$ & $\begin{array}{l}25.2 \\
\sim 72.0\end{array}$ \\
\hline
\end{tabular}

$81.25 \mathrm{mg} \mathrm{kg}^{-1} \sim 0.95 \mathrm{mg} \mathrm{kg}^{-1}$. The contribution rates of the atmospheric deposition of the soil were $10.1 \sim 11.3 \%$. This result was generally smaller compared to the monitoring value. One reason for this was that the heavy metal content of zinc ore and coal was not fixed, and we only used one parameter in the Gaussian model (Hao et al., 2010). Another reason was that the monitoring atmospheric deposition was included in the soil mineral source, traffic source, and other sources of pollution.

The total concentration of cadmium in the soil comprises the contribution from the geological parent material together with inputs from extraneous sources, which, for the most part, were anthropogenic in origin. Compared to other studies, our results were significantly higher; for example, $\mathrm{Cd}$ content was $1.51 \mathrm{mg} \mathrm{kg}^{-1}$ here, but it was just $23.5 \mathrm{\mu g} \mathrm{kg}^{-1}$ in the industrial area and $3.46 \mu \mathrm{g} \mathrm{kg}^{-1}$ in the nonindustrial area (Cao et al., 2020). As Xie et al. (2019) reported, the contribution of atmospheric deposition to soil $\mathrm{Cd}, \mathrm{Pb}$, and $\mathrm{Zn}$ input in nonindustrial areas was $50.3,70.3$, and $36.5 \%$, respectively, while the atmospheric heavy metal input flux was lower than in our context. This was because the soil heavy metal concentration was generally lower in such studies. We can conclude that the increments of heavy metal content from the atmospheric deposition on soil grow quickly within the zinc smelting plant pollution area.

We estimated the superposition of the atmospheric deposition of heavy metals in soil based on the 24 million tons of waste residue from historical indigenous zinc smelting from 30 years ago. We estimated that heavy metals deposited in the soil reached $0.56 \sim 2.08$ $\times 10^{4} \mathrm{t}(\mathrm{Cd}), 1.02 \sim 5.20 \times 10^{4} \mathrm{t}(\mathrm{Pd}), 2.00 \sim 4.71 \times 10^{4} \mathrm{t}(\mathrm{Cr}), 1.00$ $\sim 2.46 \times 10^{4} \mathrm{t}(\mathrm{Cu}), 0.89 \sim 3.32 \times 10^{4} \mathrm{t}(\mathrm{Ni})$, and $25.2 \sim 72.0 \times 10^{4} \mathrm{t}$ (Zn), respectively (Table 5) (Xia and Huang, 2011; Shang, 2012). In the absence of pollution treatment of waste gas, water, and residue, large-scale historical indigenous zinc smelting in northwest Guizhou Province could have more serious superposition effects on soil heavy metal pollution than we expected.

\section{CONCLUSION}

Soil heavy metals $\mathrm{Cd}, \mathrm{Pb}$, and $\mathrm{Zn}$ were much higher than local background values in the context of geochemical anomaly in northwest Guizhou Province. Heavy metals from atmospheric deposition were higher in the zinc smelting plant watershed than in the control watershed, and after 13 years of deposition the contribution rate of atmospheric deposition on topsoil was lowest for $\mathrm{Ni}$, at $5.10 \%$, and highest for $\mathrm{Cd}$, at $17.9 \%$. The spatial distribution of soil heavy metal indicates that the content of heavy metals in soil was highly coupled with the location of zinc smelting in MS watershed. Combined with the principal component analysis of atmospheric deposition and soil heavy metal, it can be concluded that zinc smelting atmospheric deposition showed superposition effects on the accumulation of heavy metals in topsoil under the geochemical anomaly in this area.

\section{DATA AVAILABILITY STATEMENT}

The original contributions presented in the study are included in the article/Supplementary Material, further inquiries can be directed to the corresponding author.

\section{AUTHOR CONTRIBUTIONS}

EY: Formal analysis, Data curation, Writing-Original Draft, Writing-Review and Editing, Visualization; HL: Conceptualization, Validation, Resources, Funding acquisition; YT, XG, XR: Methodolog, Investigation, Project administration; PW, ZY: Supervision.

\section{FUNDING}

This project was supported by the China National Natural Science Foundation (42067028); the National Natural Science Foundation of China and Guizhou Province (U1612442); the National Key Research and Development Plan Project (2018YFC1802602); and the Guizhou Province Science and Technology Planning Project (Qiankehehoubuzu (2020) 3001). 


\section{REFERENCES}

Adimalla, N. (2020). Heavy Metals Contamination in Urban Surface Soils of Medak Province, India, and its Risk Assessment and Spatial Distribution. Environ. Geochem. Health 42 (1), 59-75. doi:10.1007/s10653-019-00270-1

Al-Khashman, O. A., Jaradat, A. Q., and Salameh, E. (2013). Five-year Monitoring Study of Chemical Characteristics of Wet Atmospheric Precipitation in the Southern Region of Jordan. Environ. Monit. Assess. 185, 5715-5727. doi:10. 1007/s10661-012-2978-1

Cai, K., Li, C., and Na, S. (2019). Spatial Distribution, Pollution Source, and Health Risk Assessment of Heavy Metals in Atmospheric Depositions: a Case Study from the Sustainable City of Shijiazhuang, China. Atmosphere 10 (4), 222. doi:10.3390/atmos10040222

Cao, X., Tan, C., Wu, L., Luo, Y., He, Q., Liang, Y., et al. (2020). Atmospheric Deposition of Cadmium in an Urbanized Region and the Effect of Simulated Wet Precipitation on the Uptake Performance of rice. Sci. Total Environ. 700, 134513. doi:10.1016/j.scitotenv.2019.134513

Cereceda-Balic, F., Gala-Morales, M. d. 1., Palomo-Marín, R., Fadic, X., Vidal, V., Funes, M., et al. (2020). Spatial Distribution, Sources, and Risk Assessment of Major Ions Ad Trace Elements in Rainwater at Puchuncaví Valley, Chile: The Impact of Industrial Activities. Atmos. Pollut. Res. 11 (6), 99-109. doi:10.1016/j. apr.2020.03.003

Chai, L., Wang, Y. H., and Wang, X. (2021). Pollution Characteristics, Spatial Distributions, and Source Apportionment of Heavy Metals in Cultivated Soil in Lanzhou, China. Ecol. Indicators 125, 107507. doi:10.1016/J.ECOLIND.2021. 107507

Chen, L., Zhou, S., Wu, S., Wang, C., Li, B., Li, Y., et al. (2018). Combining Emission Inventory and Isotope Ratio Analyses for Quantitative Source Apportionment of Heavy Metals in Agricultural Soil. Chemosphere 204, 140-147. doi:10.1016/j.chemosphere.2018.04.002

Chen, X., Yang, Z. F., and Chen, Y. (2019). Cadmium Input Flux in farmland Soil of Nine Counties in Middle and East Guangxi. Geophys. Geochemical Exploration 43 (02), 415-427. doi:10.11720/wtyht.2019.139

Cui, X. T., Luan, W., and Li, S. (2012). An Analysis of the Sources of Heavy Metals in Atmospheric Dust Fall of Shijiazhuang City. Geology. China 39 (4), 1108-1114. doi:10.14050/j.cnki.1672-9250.2012.03.004

de P. Pereira, P. A., Lopes, W. A., Carvalho, L. S., da Rocha, G. O., de Carvalho Bahia, N., Loyola, J., et al. (2007). Atmospheric Concentrations and Dry Deposition Fluxes of Particulate Trace Metals in Salvador, Bahia, Brazil. Atmos. Environ., 41, 7837-7850. doi:10.1016/j.atmosenv.2007.06.013

Garg, B. D., Cadle, S. H., Mulawa, P. A., Groblicki, P. J., Laroo, C., and Parr, G. A. (2000). Brake Wear Particulate Matter Emissions. Environ. Sci. Technol. 34, 4463-4469. doi:10.1021/es001108h

Gu, H., Zhao, T., and Sun, R. G. (2021). Pollution Characteristics and Source Analysis of Heavy Metals in Soils of a Typical Lead-zinc Mining Area in Guizhou Province. Earth and Environment 1-10. doi:10.14050/j.cnki.16729250.2022.50.003

Hao, J. M., Ma, G. D., and Wang, S. X. (2010). Air Pollution Control Engineering. Third Edition. Beijing: Higher Education Press5

He, S. L., and Chen, Z. (2002). The Zoning of Surface Tectonic Geochemistry in Guizhou and its Significance. Guizhou Geology. 03, 148-155.

Hermanson, M. H., Isaksson, E., Hann, R., Teixeira, C., and Muir, D. C. G. (2020). Atmospheric Deposition of Organochlorine Pesticides and Industrial Compounds to Seasonal Surface Snow at Four Glacier Sites on Svalbard, 2013-2014. Environ. Sci. Technol. 54 (15), 9265-9273. doi:10.1021/acs.est. 0c01537

Hernández-Pellón, A., and Fernández-Olmo, I. (2019). Airborne Concentration and Deposition of Trace Metals and Metalloids in an Urban Area Downwind of a Manganese alloy Plant. Atmos. Pollut. Res. 10 (3), 712-721. doi:10.1016/j.apr. 2018.11.009

Kara, M., Dumanoglu, Y., Altiok, H., Elbir, T., Odabasi, M., and Bayram, A. (2014). Seasonal and Spatial Variations of Atmospheric Trace Elemental Deposition in the Aliaga Industrial Region, Turkey. Atmos. Res. 149, 204-216. doi:10.1016/j. atmosres.2014.06.009

Kiyoshi, M., Keisuke, S., and Yuuya, W. (2019). Water-soluble and WaterInsoluble Organic Nitrogen in the Dry and Wet Deposition. Atmos. Environ. 218, 117022. doi:10.1016/j.atmosenv.2019.117022
Li, S., and Jia, Z. (2018). Heavy Metals in Soils from a Representative Rapidly Developing Megacity (SW China): Levels, Source Identification and Apportionment. Catena 163, 414-423. doi:10.1016/j.catena.2017.12.035

Li, X. H. (2020). Effects of Environmental Factors on Heavy Metal Release and Biological Effects in Lead-Zinc Smelting Slag. [Master's Thesis]. Gui Yang, China: Guizhou University.

Li, Z. G., Feng, X. B., Bi, X. Y., Sun, G. Y., Zhu, J. M., Qin, H. B., et al. (2013). Heavy Metals in the Ground Surface Dust and Agricultural Soil in Artisanal and Medium-Scale Zinc Smelting Area in Northwest Guizhou Province, China. E3S Web of Conferences 1, 19004. doi:10.1051/e3sconf/20130119004

Liang, J. N., Liu, J., Chen, J., et al. (2014). Characteristics of Heavy Metals in Atmospheric Deposition in Heating Periods of an Industrial Park in Western Shanxi Province, China. Acta Scientiea Circumstantiae 34 (2), 318-324. doi:10. 13671/j.hjkxxb.2014.02.015

Liu, F. Z., Hu, J. L., and Liu, J. S. (2018). Spatial Distribution and Risk Assessment of Heavy Metals in Soil in the Metal Mining Area of Paojinshan, Hunan, China. J. Agro-Environment Sci. 37 (1), 86-95.

Luo, K., Liu, H., Liu, Q., Tu, Y., Yu, E., and Xing, D. (2020). Cadmium Accumulation and Migration of 3 Peppers Varieties in Yellow and limestone Soils under Geochemical Anomaly. Environ. Technol. 29, 1-11. doi:10.1080/09593330.2020.1772375

Luo, K., Liu, H., Zhao, Z., Long, J., Li, J., Jiang, C., et al. (2019). Spatial Distribution and Migration of Cadmium in Contaminated Soils Associated with a Geochemical Anomaly: A Case Study in Southwestern China. Pol. J. Environ. Stud. 28 (5), 3799-3807. doi:10.15244/pjoes/94847

Luo, Y., Wu, Y., Wang, H., Xing, R., Zheng, Z., Qiu, J., et al. (2018). Bacterial Community Structure and Diversity Responses to the Direct Revegetation of an Artisanal Zinc Smelting Slag after 5 Years. Environ. Sci. Pollut. Res. 25, 14773-14788. doi:10.1007/s11356-018-1573-6

Ministry of Environmental Protection (2014). Water Quality - Digestion of Total Metals - Microwave Assisted Acid Digestion Method(HJ 678-2013).

Pan, Y., Liu, J., Zhang, L., Cao, J., Hu, J., Tian, S., et al. (2021). Bulk Deposition and Source Apportionment of Atmospheric Heavy Metals and Metalloids in Agricultural Areas of Rural Beijing during 2016-2020. Atmosphere 12 (2), 283. doi:10.3390/ATMOS12020283

Pan, Y. P., and Wang, Y. S. (2015). Atmospheric Wet and Dry Deposition of Trace Elements at 10 Sites in Northern China. Atmos. Chem. Phys. 15, 951-972. doi:10.5194/acp-15-951-2015

Peng, Y., Chen, J., Wei, H., Li, S., Jin, T., and Yang, R. (2018). Distribution and Transfer of Potentially Toxic Metal(loid)s in Juncus Effusus from the Indigenous Zinc Smelting Area, Northwest Region of Guizhou Province, China. Ecotoxicology Environ. Saf. 152, 24-32. doi:10.1016/j.ecoenv.2018. 01.026

Qiu, K., Xing, W., Scheckel, K. G., Cheng, Y., Zhao, Z., Ruan, X., et al. (2016). Temporal and Seasonal Variations of as, $\mathrm{Cd}$ and $\mathrm{Pb}$ Atmospheric Deposition Flux in the Vicinity of lead Smelters in Jiyuan, China. Atmos. Pollut. Res. 7 (1) 170-179. doi:10.1016/j.apr.2015.09.003

Shamsaddin, H., Jafari, A., Jalali, V., and Schulin, R. (2020). Spatial Distribution of Copper and Other Elements in the Soils Around the Sarcheshmeh Copper Smelter in southeastern Iran. Atmos. Pollut. Res. 11 (10), 1681-1691. doi:10. 1016/j.apr.2020.07.002

Shang, X. H. (2012). Environmental Impact of Old-Styled Zinc Smelting and its Solution in Mile County. Environ. Sci. Surv. 31 (4), 76-78. doi:10.13623/j.cnki. hkdk.2012.04.027

Sonia, C., Jesús, D., and Ana, M. (2013). Heavy Metal Deposition Fluxes Affecting an Atlantic Coastal Area in the Southwest of Spain. Atmos. Environ 77, 509-517. doi:10.1016/j.atmosenv.2013.05.046

State Bureau of Environmental Protection. (1994). Technical Guidelines for Environmental Impact Assessment-Atmospheric Environment(HJ/T 2.1 2.393). Bei Jing, China: China Environmental Science Press

State Environmental Protection Administration of China. (2004). The Technical Specification for Environmental monitoring(HJ/T 166 -2004). Bei Jing, China: China Environmental Science Press

Sternbeck, J., Sjödin, A., and Andréasson, K. (2002). Metal Emissions from Road Traffic and the Influence of Resuspension-Results from Two Tunnel Studies. Atmos. Environ. 36, 4735-4744. doi:10.1016/S1352-2310(02)00561-7

Vallius, M., Lanki, T., Tiittanen, P., Koistinen, K., Ruuskanen, J., and Pekkanen, J. (2003). Source Apportionment of Urban Ambient PM2.5 in Two Successive 
Measurement Campaigns in Helsinki, Finland. Atmos. Environ. 37, 615-623. doi:10.1016/S1352-2310(02)00925-1

Wang, J., Huang, Y., Li, T., He, M., Cheng, X., Su, T., et al. (2020). Contamination, Morphological Status and Sources of Atmospheric Dust in Different LandUsing Areas of a Steel-Industry City, China. Atmos. Pollut. Res. 11 (2), 283-289. doi:10.1016/j.apr.2019.10.014

Wang, J., Zhang, X., Yang, Q., Zhang, K., Zheng, Y., and Zhou, G. (2018). Pollution Characteristics of Atmospheric Dustfall and Heavy Metals in a Typical Inland Heavy Industry City in China. J. Environ. Sci. 71 (9), 283-291. doi:10.1016/j.jes. 2018.05.031

Wang, Q., Xie, Z., and Li, F. (2015). Using Ensemble Models to Identify and Apportion Heavy Metal Pollution Sources in Agricultural Soils on a Local Scale. Environ. Pollut. 206, 227-235. doi:10.1016/j.envpol.2015.06.040

Xia, X., Yang, Z., Cui, Y., Li, Y., Hou, Q., and Yu, T. (2014). Soil Heavy Metal Concentrations and Their Typical Input and Output Fluxes on the Southern Song-Nen Plain, Heilongjiang Province, China. J. Geochemical Exploration 139, 85-96. doi:10.1016/j.gexplo.2013.06.008

Xia, Y., and Huang, M. J. (2011). Risk Assessment on Abandoned Traditional Smelting Zinc Sites in Bijie Prefecture. Guizhou Agric. Sci. 39 (8), 218-222. doi:10.1016/j.enpol.2011.03.051

Xie, G. X., Ying, J. Y., and Zhang, M. K. (2019). Mass Balance of Heavy Metals in Typical Pear Orchard Ecological System Affected by Fertilization and Atmospheric Deposition. Chin. Agric. Bull. 35 (16), 88-94.

Xing, W., Yang, H., Ippolito, J. A., Zhang, Y., Scheckel, K. G., and Li, L. (2020b). Lead Source and Bioaccessibility in Windowsill Dusts within a Pb Smelting-Affected Area. Environ. Pollut. 266, 115110. doi:10.1016/j.envpol. 2020.115110

Xing, W., Yang, H., Ippolito, J. A., Zhao, Q., Zhang, Y., Scheckel, K. G., et al. (2020a). Atmospheric Deposition of Arsenic, Cadmium, Copper, lead, and Zinc Near an Operating and an Abandoned lead Smelter. J. Environ. Qual. 49 (6), 1667-1678. doi:10.1002/jeq2.20151

Yasser, M. G., Jesús, M. S., and David, E. (2019). Determination and Source Apportionment of Major and Trace Elements in Atmospheric Bulk Deposition in a Caribbean Rural Area. Atmos. Environ. 202, 93-204. doi:10.1016/j. atmosenv.2019.01.019

Yi, K., Fan, W., Chen, J., Jiang, S., Huang, S., Peng, L., et al. (2018). Annual Input and Output Fluxes of Heavy Metals to Paddy fields in Four Types of Contaminated Areas in Hunan Province, China. Sci. Total Environ. 634, 67-76. doi:10.1016/j.scitotenv.2018.03.294
Yu, E. J., and Liu, H. Y. (2021). Effect of Atmospheric Deposition on Cadmium Accumulation in Soils: a Review. Environ. Anal. Eco. Stud. 8 (1), 432-846. doi:10.31031/EAES.2021.08.000676

Yu, Z., Chen, F., and Zhang, J. J. (2019). Contamination and Risk of Heavy Metals in Soils and Vegetables from Zinc Smelting Area. China Environ. Sci. 39 (5), 2086-2094. doi:10.19674/j.cnki.issn1000-6923.2019.0250

Zhang, S., and Song, J. (2018). Geochemical Cadmium Anomaly and Bioaccumulation of Cadmium and lead by Rapeseed (Brassica Napus L.) from Noncalcareous Soils in the Guizhou Plateau. Sci. Total Environ. 644, 624-634. doi:10.1016/j.scitotenv.2018.06.230

Zhang, W., Long, J., Wei, Z., and Alakangas, L. (2016). Vertical Distribution and Historical Loss Estimation of Heavy Metals in an Abandoned Tailings Pond at HTM Copper Mine, Northeastern China. Environ. Earth Sci. 75 (22), 1462. doi:10.1007/s12665-016-6271-4

Zheng, X., Guo, X., Zhao, W., Shu, T., Xin, Y., Yan, X., et al. (2016). Spatial Variation and Provenance of Atmospheric Trace Elemental Deposition in Beijing. Atmos. Pollut. Res. 7 (2), 260-267. doi:10.1016/j.apr.2015.10.006

Zhou, Y., Wang, L., Xiao, T., Chen, Y., Beiyuan, J., She, J., et al. (2020). Legacy of Multiple Heavy Metal(loid)s Contamination and Ecological Risks in farmland Soils from a Historical Artisanal Zinc Smelting Area. Sci. Total Environ. 720, 137541. doi:10.1016/j.scitotenv.2020.137541

Conflict of Interest: The authors declare that the research was conducted in the absence of any commercial or financial relationships that could be construed as a potential conflict of interest.

Publisher's Note: All claims expressed in this article are solely those of the authors and do not necessarily represent those of their affiliated organizations, or those of the publisher, the editors and the reviewers. Any product that may be evaluated in this article, or claim that may be made by its manufacturer, is not guaranteed or endorsed by the publisher.

Copyright (c) $2022 \mathrm{Yu}, \mathrm{Liu}, \mathrm{Tu}, \mathrm{Gu}, \mathrm{Ran}, \mathrm{Yu}$ and $\mathrm{Wu}$. This is an open-access article distributed under the terms of the Creative Commons Attribution License (CC BY). The use, distribution or reproduction in other forums is permitted, provided the original author(s) and the copyright owner(s) are credited and that the original publication in this journal is cited, in accordance with accepted academic practice. No use, distribution or reproduction is permitted which does not comply with these terms. 